\title{
Empowering Ability in Disability--Avoiding the Web of Disability
}

Mohammed Ranavaya, MD, JD ${ }^{1}$

\section{Author Affiliations:}

1. Marshall University Joan C. Edwards School of Medicine, Huntington, WV

The author has no conflicts of interest to disclose

\section{Corresponding Author:}

Mohammed Ranavaya, MD, JD, MS, FRCPI, FFOM, CIME Professor and Chief Division of Occupational, Environmental and Disability Medicine Joan C. Edwards School of Medicine at Marshall University

Email: ranavaya@marshall.edu 


\section{Empowering Ability in Disability--Avoiding the Web of Disability}

Tolerance of and care for the sick and the disabled are the elemental components of our social fabric, rooted in the very origins of human society. The concept of providing welfare, maintenance, and protection for people with disabilities is hardly a contemporary one; historical evidence documents that social justice and succor for individuals with disabilities have been around since recorded history. All major religions including Islam, Christianity, Hinduism, Buddhism, Judaism, Taoism etc. have commanded their followers to do the same.

It's estimated nearly one billion people live with disabilities worldwide. Disability is part of the human existence and empowering ability in disability would require all of us to rethink, from the ways we design our communities and homes, to how we as citizens support equal access and inclusion in the places we live and work.

This change needs to be done both at macro and micro level. The macro level being the Community and Society at large as well as the disability and compensation systems, including employers. The micro level is the individual with disability or different ability.

For far too long, the individual with disability has been patronized and at times feared at the macro level for causing harm to themselves or others leading to exclusion. The fear leads to protection and palliative approach to rehabilitation that augments disability rather than reducing it. Identifying fear and refusing to obey it is the source of all true empowerment.

The process of empowering ability in disability requires that each one of us be mindful that all people are created equal; therefore, each person has intrinsic value not based on what they can do but on who they are. The old and wise Chinese proverb "honor one, honor alldisgrace one, disgrace all" sums it all up.

Good scientific data supports the notion that society pays a cost when persons with disabilities can't participate. The stigma associated with labeling someone disabled, no matter how well intentioned, is harmful to all and we need to disable the label. We as a society need to rethink and redefine our attitudes and our laws towards persons of all abilities and celebrate the strengths in weakness rather than focus on it.

At the level of individual, to avoid falling into the web of disability, the autonomy of the person is the key. The focus should be on early intervention after injury; all medically appropriate, timely intervention should be provided with the individual empowered to selfdetermine the treatment. It is critical that the claims related disputes and other administrative issues be resolved in an expeditious manner without unnecessary litigation.

Other than some very catastrophic injuries, all individuals regardless of the injury have some ability that can lead to productive and fulfilling life. Empowering ability in disability means independence in personal, social, and economic aspects of life. Peer reviewed scientific literature is replete with data that supports the conclusion that prolonged absence from one's normal roles, including absence from the work place, is detrimental to a person's mental, physical, and social wellbeing. Several well designed studies have shown that worklessness (being unemployed or economically inactive and in receipt of welfare or social service benefits) causes poor health and health inequality, and that this effect is still seen after adjustment for social class, poverty, age, and preexisting morbidity. 
All of us endeavoring to empower ability in disability need to be sensitive to the fact that work is part of what gives life meaning and purpose to an individual, as well as what provides the income for life's necessities, i.e. food, shelter, clothing and other care. People who are out of work experience a much poorer quality of life. They are three times more likely to suffer from poor mental health, in particular depression and anxiety and are found to have increased incidence of drug and alcohol abuse, including smoking and risk taking sexual behavior. It is well documented that Worklessness not only leads to increased morbidity but also to increased mortality.

Avoiding these preventable secondary health conditions and early return to gainful employment after an injury is the true empowerment of the individual with disability. 